\title{
Processo de Significação de Estudantes do Curso de Medicina diante da Escolha Profissional e das Experiências Vividas no Cotidiano Acadêmico
}

\author{
Motivations for Career-Choice and \\ Experiences of the Academic Day-to-Day \\ Life of Medical Students
}

\author{
Simone da Nóbrega Tomaz Moreira ${ }^{1}$ \\ Cleyton Amaral Nogueira e Silva ${ }^{2}$ \\ Franklin de Freitas Tertulino ${ }^{2}$ \\ Fabiana Michelle de Freitas Tertulino ${ }^{2}$ \\ Maria José Pereira Vilar ${ }^{3}$ \\ George Dantas de Azevedo ${ }^{4}$
}

PALAVRAS-CHAVE

- Educação Médica;

- Análise Qualitativa;

- Escolha da Profissão;

- Estudantes de Medicina.

KEY-WORDS

- Education, Medical;

- Qualitative Analysis;

- Career Choice;

- Students, Medical.

Recebido em: 03/01/2006

Aprovado em: 19/04/2006

$14 \mid \frac{\text { REVISTA BRASILEIRA DE EDUCAÇÃO MÉDICA }}{30(2): 14-19 ; 2006}$

\footnotetext{
${ }^{1}$ Universidade Federal do Rio Grande do Norte, Natal, Rio Grande do Norte, Brasil.

${ }^{2}$ Universidade Federal do Rio Grande do Norte, Natal, Rio Grande do Norte, Brasil.

${ }^{3}$ Departamento de Medicina Clínica, Universidade Federal do Rio Grande do Norte, Natal, Rio Grande do Norte, Brasil.

${ }^{4}$ Departamento de Morfologia, Universidade Federal do Rio Grande do Norte, Natal, Rio Grande do Norte, Brasil.
}

The purpose of this study is to perform an extensive analysis of career-choice motivations of medical students at the Federal University of Rio Grande do Norte, Natal, Brazil, and to understand their daily academic experiences. The methodology employed was qualitative, using semi-structured interviews. The sample consisted of 30 students from the 1st to the 6th year of the course, uniformly selected from the different course levels. The data were analyzed by means of content analysis. This analysis revealed that factors that influenced the students in the choice of the medicine course were family influence, personal identification, the search for financial independence and professional status as well as the desire to help and to be useful. In relation to moments experienced during the course, the recognition of family and friends, experiences with patients and contact with competent professors were cited as the most gratifying, while extensive examinations and insufficient time for studying, uninspiring classes 
given by outdated professors, contact with terminal patients and death along with physical exhaustion were considere the most distressing moments. The data point to important aspects in the daily life of medical students that may help to determine psychopedagogic support strategies in future curricular guidelines.

\section{INTRODUÇÃO}

Vencidas as dificuldades e os desafios inerentes à fase préuniversitária, como cursinhos, pressão social, medo de não corresponder às expectativas dos pais e forte concorrência do concurso vestibular, o estudante de Medicina comumente chega à faculdade repleto de sonhos, fantasias e com um ideal: tornar-se um médico respeitado e admirado.

Segundo Millan et al. ${ }^{1}$, a faculdade é vista pelo aluno como o continente idealizado, onde não mais haverá angústia, insegurança ou exigências; pelo contrário, será o lugar onde suas expectativas serão satisfeitas e que possibilitará, finalmente, realizar o desejo de ser médico, muitas vezes presente desde a infância.

Entretanto, no decorrer do curso, do primeiro ao sexto ano, incluindo-se aí a difícil escolha da especialidade, o caminho é longo e árduo, podendo trazer frustrações, sofrimentos e medos. Tais sentimentos, quando não adequadamente elaborados, podem ser motivo de eventuais transtornos na esfera psicológica; por outro lado, quando não são negados ou negligenciados, podem se transformar em oportunidades de aprendizagem e de descobertas sobre a condição humana ${ }^{2,3}$.

A análise dos fatores que motivam a escolha do curso médico tem causado interesse dos pesquisadores em Educação Médica. Nesse sentido, o objetivo do nosso estudo é empreender uma análise aprofundada das motivações dos estudantes para a escolha profissional, como também compreender suas vivências no cotidiano acadêmico.

\section{METODOLOGIA}

Foi realizado estudo com abordagem qualitativa, utilizando-se a técnica de associação livre, por meio de entrevista semi-estruturada. A casuística foi constituída por 30 estudantes do primeiro ao sexto ano do curso de Medicina da Universidade Federal do Rio Grande do Norte, Natal (RN), distribuídos eqüitativamente entre as diferentes fases do curso. O estudo foi aprovado pelo Comitê de Ética em Pesquisa da Universidade Federal do Rio Grande do Norte, e os participantes assinaram termo de consentimento livre e esclarecido, após informação detalhada sobre os propósitos da pesquisa.

Para caracterizar a população do estudo, foi utilizada uma Ficha de Identificação, que incluiu questões sobre idade, sexo, religião, estado civil e nível em que se encontrava no curso. Com o propósito de identificar os motivos que levaram os estudan- tes a escolherem o curso de Medicina, como também de compreender a significação dos alunos diante de situações angustiantes e/ou gratificantes vividas no decorrer do curso, os participantes responderam a um questionário semi-estruturado.

Os dados foram analisados por meio da técnica análise de conteúdo temática-7. Nesse sentido, o processo analítico compreendeu as seguintes fases: leitura flutuante, constituição do corpus e formulação de hipóteses e objetivos.

A leitura flutuante consistiu no contato exaustivo com o material, deixando-se impregnar por seu conteúdo. A dinâmica entre as hipóteses iniciais, as hipóteses emergentes e as teorias relacionadas ao tema tornou a leitura progressivamente mais sugestiva e capaz de ultrapassar a sensação de caos inicial.

Na constituição do corpus, ocorreu a organização do material de forma que respondesse a algumas normas de validade, tais como: exaustividade (contemplar todos os aspectos levantados no roteiro), representatividade (conter a representação do universo pretendido), homogeneidade (obedecer a critérios precisos de escolha em termos de temas, técnicas e interlocutores), pertinência (o material analisado estar adequado aos objetivos do trabalho).

A formulação de hipóteses e objetivos consistiu na seleção das unidades de análise, por meio da qual emergiram categorias, que foram descritas e discutidas a partir do referencial teórico ${ }^{7}$.

\section{RESULTADOS E DISCUSSÃO}

\section{Caracterização da amostra}

O grupo estudado constou de 30 estudantes, sendo 16 (53\%) do sexo feminino e 14 (47\%) do masculino. A média de idade foi de 22,03 $\pm 2,04$ anos. Em relação ao estado civil, apenas uma estudante (3\%) estava casada, enquanto 29 (97\%) estudantes eram solteiros. Em relação à religião, evidenciou-se predomínio de estudantes católicos ( $n=22,73 \%$ ), seguidos de evangéli$\cos (n=03,10 \%)$, dos que se declararam sem religião $(n=03$, $10 \%$ ) e de 2 estudantes (7\%) que disseram ser espíritas.

\section{Categorização do material}

A partir do processo de categorização a posteriori ou empírica, emergiram 3 categorias, 12 subcategorias e 108 unidades de análise, conforme observado na Tabela 1. Considerando-se que não constitui objetivo do trabalho quantificar os fatores analisados em ordem de freqüência, mas, sim, compreender as vivências sobre os aspectos pesquisados, optouse por não apresentar as subcategorias pela ordem de freqüência com que emergiram, mas, sim, analisar cada uma delas isoladamente, à luz do referencial teórico, para atingir, mediante a inferência, uma interpretação mais profunda. 
TABELA 1

Distribuição das categorias e subcategorias

\begin{tabular}{|c|c|c|}
\hline Categorias & Subcategorias & $\begin{array}{l}\mathrm{N}^{\circ} \text { de unidades } \\
\text { de análise }\end{array}$ \\
\hline \multirow{5}{*}{ 1. Motivação da escolha profissional } & 1.1 Influência familiar & 05 \\
\hline & 1.2 Independência financeira & 16 \\
\hline & 1.3 Identificação pessoal & 19 \\
\hline & 1.4 Status profissional & 06 \\
\hline & 1.5 Ajudar as pessoas & 10 \\
\hline \multirow{3}{*}{$\begin{array}{l}\text { 2. Momentos mais gratificantes vividos } \\
\text { durante o curso }\end{array}$} & 2.1 Reconhecimento família/amigos & 04 \\
\hline & 2.2 Experiência com o paciente & 22 \\
\hline & 2.3 Contato com professores-modelo & 04 \\
\hline \multirow{4}{*}{$\begin{array}{l}\text { 3. Momentos angustiantes vividos } \\
\text { durante o curso }\end{array}$} & 3.1 Provas extensas e pouco tempo para estudo & 16 \\
\hline & 3.2 Aulas monótonas e professores desatualizados & 07 \\
\hline & 3.3 Contato com pacientes terminais e com a morte & 06 \\
\hline & 3.5 Cansaco físico & 03 \\
\hline
\end{tabular}

\section{MOTIVAÇÃO DA ESCOLHA PROFISSIONAL}

Quanto à motivação para a escolha do curso de Medicina, a análise permite identificar que são vários os fatores determinantes, entre os quais se podem destacar a influência familiar, identificação pessoal, busca da independência financeira e de status profissional e, ainda, o desejo de ajudar e de ser útil às pessoas. A análise aprofundada dos relatos demonstrou que esses fatores não se apresentaram de forma isolada, conforme comprovam as expressões dos entrevistados a seguir:

(...) Sempre quis desde pequena, meu pai é médico, sempre convivi nesse ambiente e só me via fazendo isso, além do retorno financeiro que a profissão te dá e da possibilidade de ajudar pessoas.

(...) curiosidade em relação ao corpo humano, admiração pela forma como os médicos são tratados, além da remuneração.

(...) Porque é um dos cursos que eu vejo que, além de ter um mercado de trabalho que simplesmente não tem fronteiras, ele consegue ser apaixonante e ao mesmo tempo posso ajudar pessoas a ter uma qualidade de vida melhor.
Segundo Millan et al. ${ }^{1}$, a escolha profissional pode ser analisada por meio das motivações de natureza consciente e inconsciente. Vários autores ${ }^{8}$ têm dado relevância à motivação existente no processo da seleção profissional, em virtude das inúmeras variáveis envolvidas e das implicações inerentes à escolha mal sucedida. Ao lado desses aspectos, podem-se mencionar as crenças dos estudantes, que são reforçadas por fatores socioculturais acerca do status da Medicina, conforme expressam as falas a seguir:

(...) profissão bonita e de prestígio, sendo mais fácil me realizar profissionalmente no sentido de sucesso.

(...) o curso me dará habilidades para curar e salvar uma vida.

(...) sendo um bom médico, você é valorizado e respeitado.

Além disso, foi representativo o número de estudantes que destacaram a independência financeira como agente motivador da escolha profissional:

(...) é um dos poucos cursos que apresenta um mercado de trabalho simplesmente sem fronteiras. 
(...) profissão com mercado de trabalho amplo, assim terei minha autonomia sem depender de uma pessoa para me empregar.

(...) eu escolhi fazer Medicina pela independência financeira que é garantida no final do curso.

Entretanto, Arruda \& Millan ${ }^{9}$ afirmam que, nos dias de hoje, com as dificuldades que o médico enfrenta em seu cotidiano profissional (vários empregos, má remuneração, más condições de trabalho, etc.), aliadas à redução do prestígio social da categoria, fica difícil para o estudante conciliar a ilusão construída com a realidade vivenciada.

Esses autores classificaram as motivações da escolha profissional em três núcleos distintos: (1) interesse humanitário: desejo de cuidar, de curar, de se dedicar, prazer por contatos; (2) interesse científico: pela biologia, ciências experimentais e humanas, interesse científico teórico; e (3) posição socioeconômica: interesse pecuniário, posição social, busca de prestígio, desejo de segurança pessoal.

Alguns autores 9,10 enfatizam que o indivíduo escolhe ser médico pelo desejo de ajudar ou por vocação profissional, e o ideal médico deve-se constituir na vontade de socorrer, no amor ao próximo e no espírito de sacrifício. Um estudo desenvolvido por Mascaretti et al. ${ }^{11}$ aponta que o principal motivo da escolha profissional é o desejo de ajudar as pessoas. Tal fato foi reforçado pelos dados da presente pesquisa, em que os estudantes afirmaram ter escolhido estudar Medicina pelo desejo de serem úteis e necessários às pessoas, conforme demonstrado nas seguintes falas:

(...) questão puramente pessoal, achei que fosse a melhor profissão para eu ajudar as pessoas.

(...) vocação, e por gostar de me sentir útil e necessária.

(...) sempre admirei a arte de curar e aliviar o sofrimento dos outros.

É necessário destacar que, além de todas as motivações citadas, existem os fatores individuais, que são frutos da história de vida de cada um.

Momentos gratificantes vividos durante o curso

Após o sucesso no concorrido concurso vestibular, o estudante chega à faculdade com a expectativa de que não haverá mais angústias ou exigências, e de que, pelo contrário, a faculdade será o lugar adequado ao desenvolvimento das habilidades necessárias à prática profissional. Essa expectativa é corroborada pela recepção dada pelos veteranos, além do entusiasmo da família, que se orgulha por ter um de seus membros como estudante de Medicina ${ }^{1}$. Alguns entrevistados afirmaram que o reconhecimento familiar e de amigos constitui um dos momentos mais gratificantes vividos durante o curso, conforme observado nas falas a seguir:
(...) momento legal é quando os pais te reconhecem, os amigos te reconhecem, sentem aquele orgulho, aí você se sente realmente estimulado a estudar Medicina.

(...) a melhor sensação foi ter visto o orgulho dos meus pais por eu estudar Medicina.

(...) a família reconhece o nosso esforço e te elogia.

O aluno, ao iniciar o contato com os pacientes, sente-se gratificado, conforme demonstram as seguintes falas:

(...) o melhor momento vivido no curso foi quando eu senti que o paciente confiava em mim, mesmo eu sendo estudante. (...) foi muito gratificante quando uma paciente me agradeceu por uma única conversa.

(...) é bom quando a gente percebe a confiança que o paciente deposita na figura do médico.

Apesar da satisfação sentida, o contato com o paciente traz para o estudante uma série de temores, que são justificáveis pela falta de experiência e pela insegurança na prática médica. A superação dessas dificuldades depende, em grande parte, da relação estabelecida entre professor e aluno, pois é durante a formação acadêmica que se deve procurar desenvolver nos alunos os recursos necessários para lidar com a dimensão humana da relação terapêutica.

Arruda ${ }^{12}$ concorda e acrescenta que a habilidade em estabelecer uma boa interação médico-paciente precisa ser desenvolvida ainda na formação médica, com a inclusão de abordagens que reflitam sobre a subjetividade do paciente, ou seja, sobre a pessoa do doente. Um estudo desenvolvido por Grosseman \& Patrício ${ }^{13}$ aponta que a formação acadêmica não valoriza o relacionamento interpessoal, limitando a sua formação ao aprendizado centrado no diagnóstico e tratamento de doenças.

Alguns autores ${ }^{8,14}$ destacam que mudanças curriculares em cursos de Medicina são necessárias para que a formação do profissional valorize práticas humanizadas, que permitam a compreensão do universo psicológico e social do paciente.

Nessa perspectiva, o "exemplo" do professor é fundamental para a formação da identidade profissional do aluno e para que este possa desenvolver uma postura que, na prática profissional, valorize a relação médico-paciente. A relação professor-aluno mantém íntima afinidade com a relação médico-paciente, visto que o professor, além de atuar como um modelo para o aluno (processo de identificação) por intermédio de suas atitudes, gestos e comportamentos, deve ter em mente que tais processos se repetirão no relacionamento do futuro médico com seus pacientes ${ }^{15}$. No âmbito educacional, existe uma relação definida entre atitudes e aprendizagem ${ }^{8}$, sendo reconhecida a necessidade e a importân- 
cia de o estudante incorporar atitudes positivas, ou construtivas, frente a aspectos relevantes da prática médica ${ }^{8,16}$.

O contato dos alunos com "professores-modelo" tem grande importância para a aprendizagem, que é definida como o processo psicológico da aquisição de algo, visando a determinado desempenho ${ }^{12}$. Os estudantes esperam professores que não apenas informem, mas que contribuam para a sua formação tanto pessoal quanto profissional, conforme observado nas falas de alguns entrevistados:

(...) ter aulas com professores que são exemplos de vida, para nós, alunos, estimula muito.

(...) é muito bom quando temos uma aula bem dada por um professor-modelo, em que a gente se espelhe.

(...) é muito bom o contato com professores que são exemplo e que te passam conhecimento para te fazer salvar vidas.

\section{Momentos angustiantes vividos durante o curso}

Os momentos vividos no decorrer do curso de Medicina nem sempre são gratificantes, e a fase inicial de euforia do aluno é substituída por uma fase posterior de desencanto ${ }^{1}$, com queixas freqüentes, como excessivo volume de estudos e tempo escasso, aulas monótonas e professores desatualizados, cansaço físico, além do contato com pacientes terminais e com a morte.

A administração do tempo de forma que seja possível conciliar provas e aulas representa uma das principais angústias vividas durante o curso, conforme demonstram os relatos a seguir:

(...) os piores momentos são durante o período de provas, que nunca dá tempo para estudar todo o assunto.

(...) temos pouco tempo para dar conta de uma imensidão de matéria.

(...) foi muito angustiante quando eu tive que estudar várias coisas ao mesmo tempo, como o tempo era curto, eu não sabia o que era mais importante.

(...) são as provas que temos que estudar pelas madrugadas, além da carga horária bastante estressante.

Somam-se a isso o cansaço físico e a falta de tempo para a família e o lazer, situações consideradas angustiantes para alguns estudantes, conforme observado nos seguintes relatos:

(...) se tivéssemos mais tempo para lazer e sono, acho até que produziríamos mais.

(...) às vezes, passamos a noite no plantão e saímos direto para assistir aula, não tem quem consiga aprender.

(...) não temos muito tempo para a família, muitas vezes, quando estamos em casa é dormindo.

Esses dados corroboram a afirmação de Millan et al. ${ }^{17}$ de que alunos de Medicina mencionam como principais fontes de estresse a perda da liberdade pessoal e o excesso de pressões acadêmicas, além da falta de tempo para o lazer, para estar com a família e com os amigos mais íntimos.

Existem professores que, segundo os alunos, estão desatualizados e não têm compromisso com o ensino, ministrando aulas monótonas e cansativas:

(...) são aquelas aulas que a gente não consegue ver fim, que são meio difíceis de assistir e os professores não são muito inspirados para dá-las.

(...) dá raiva a falta de interesse por parte de alguns professores, alguns são medíocres e dá desgosto de assistir suas aulas. (...) é quando você não entende nada do que o professor está falando e ele não lhe dá chance para perguntar.

Outro momento de grande angústia para os estudantes é acompanhar pacientes terminais, que os levam a entrar em contato com a própria fragilidade e finitude:

(...) foi muito angustiante no semestre passado, no Hospital Giselda*, quando me deparei com pacientes terminais que até então não tinha tido contato. ( ${ }^{*}$ Hospital de Doenças Infecciosas e Transmissíveis)

(...) o pior momento vivido no curso foi quando estava dando plantão no Giselda e um paciente com tuberculose entrou em parada cardiorrespiratória e não conseguimos fazê-lo retornar, sendo o meu primeiro contato com a morte de um paciente.

(...) foi horrível quando atendi um paciente e sabia que ele estava muito ruim, que ia morrer, passei o resto do dia muito mal.

Nossa sociedade freqüentemente lida com a morte tentando excluí-la de seu cotidiano. Essa estratégia tem sido transferida para os profissionais de saúde, de forma que muitos não conseguem estabelecer uma relação com o paciente chamado terminal e, inconscientemente, evitam a relação médico-paciente $^{18}$. Uma vez que a morte é uma constante no trabalho médico, surge, então, a seguinte questão: como os cursos de Medicina preparam o aluno para lidar com essa realidade?

Quintana et al. ${ }^{3}$ respondem a esse questionamento afirmando que os cursos de Medicina não preparam o aluno para enfrentar situações que envolvam a morte. Na verdade, o que fazem é prepará-lo para lidar com essa problemática por meio do uso de mecanismos de defesa, como a negação, a evitação e a racionalização.

\section{CONSIDERAÇÕES FINAIS}

A escolha profissional é analisada por meio de motivações conscientes e inconscientes. São muitos os fatores conscientes de- 
terminantes, como a influência familiar, o desejo de independência financeira, a identificação pessoal com o curso, além do status profissional e do desejo de ajudar as pessoas. Aliados a esses aspectos, estão os fatores de natureza inconsciente.

Quando chega à faculdade, o aluno se sente valorizado pela família e orgulhoso pela vitória conquistada no concurso vestibular, acreditando que todos os problemas terminaram e que "ser médico" é apenas uma questão de tempo. Após a fase de euforia, o estudante passa de fato a ter contato com o curso de Medicina por meio de aulas, matérias e professores. Surge, então, o desencanto pelo curso e uma infinidade de queixas - volume de provas excessivo, aulas monótonas e professores desatualizados, contato desgastante com pacientes terminais e com a morte.

Além disso, observa-se que, durante a formação médica, os momentos angustiantes são vividos, muitas vezes, de modo solitário. Concordamos com Bellodi ${ }^{19}$ quando defende a criação de um espaço na universidade, desvinculado das atividades acadêmicas, que funcione como um continente das experiências emocionais vividas pelos estudantes e que possa promover o desenvolvimento de atitudes positivas.

Cada vez mais, as escolas médicas reconhecem a necessidade de oferecer assistência psicológica a estudantes de Medicina, destacando a importância de existir um ambiente acolhedor, para auxiliar os jovens a superar suas angústias.

\section{REFERÊNCIAS}

1. Millan LR, Marco OLN, Rossi E, Millan MPB, Arruda PCV. Alguns aspectos psicológicos ligados à formação médica. In: O universo psicológico do futuro médico. São Paulo: Casa do Psicólogo; 1999.

2. Dini PS, Batista NA. Graduação e prática médica: expectativas e concepções de estudantes de Medicina do $1^{\circ}$ ao $6^{\circ}$ ano. Rev. Bras. Educ. Med. 2004; 28:198-203

3. Quintana AM, Cecim PS, Henn CG. O preparo para lidar com a morte na formação do profissional de Medicina. Rev. Bras. Educ. Med. 2002; 26: 204-10.

4. Bauer MW. Análise de conteúdo clássica: uma revisão. In: Bauer MW, Gaskell G. Pesquisa qualitativa com texto, imagem e som. Petrópolis (RJ): Vozes; 2002.

5. Chizzotti A. Pesquisa em ciências humanas e sociais. São Paulo: Cortez $3^{\circ}$ edição, 1998.

6. Bardin L. Análise do conteúdo. Lisboa: Edições 70; 1977.

7. Minayo MCS. Fase de análise ou tratamento do material. In: $\mathrm{O}$ desafio do conhecimento: pesquisa qualitativa em saúde. 7 ed. São Paulo: Hucitec; 2000.

8. Troncon LEA, Colares MFA, Figueiredo JFC, Cianflone ARL, Rodrigues MLV, Piccinato CE, Peres LC. Atitudes de graduandos em Medicina em relação a aspectos relevantes da prática médica. Rev. Bras. Educ. Med. 2003; 27: 20-8.

9. Arruda PCV, Millan, LR. Avocação médica. In: Ouniverso psicológico do futuro médico. São Paulo: Casa do Psicólogo; 1999.

10. Vieira JE, Nobre MRC, Nunes MPT, Martins MA. O perfil do aluno da faculdade de Medicina da Universidade de São Paulo. Vestibular seleciona com viés? Rev. Bras. Educ. Med. 2001; 25: 68-72.

11. Mascaretti LAS. Perfil do aluno da faculdade de Medicina de São Paulo. Rev. Bras. Educ. Med. 2002; 26 (Supl.2): 55.

12. Arruda PCV. As relações entre alunos, professores e pacientes. In: $\mathrm{O}$ universo psicológico do futuro médico. São Paulo: Casa do Psicólogo; 1999.

13. Grosseman S, Patrício ZM. A relação médico-paciente e o cuidado humano: subsídios para promoção da educação médica. Rev. Bras. Educ. Med. 2004; 28: 99-105.

14. Ronzani TM, Ribeiro MS. Identidade e formação profissional dos médicos. Rev. Bras. Educ. Med. 2003; 27: 229-36.

15. Tavares FM. As contribuições da medicina psicossomática à formação médica. Rev. Bras. Educ. Med. 2005; 29: 64-9.

16. Colares MFA, Troncon LEA, Figueiredo JFC, Cianflone ARL, Rodrigues MLV, Piccinato CE, Peres LC, Coleta JAD. Construção de um instrumento para avaliação das atitudes de estudantes de Medicina frente a aspectos relevantes da prática médica. Rev. Bras. Educ. Med. 2002; 26: 194-203

17. Millan LR, Rossi E, Marco OLN. A psicopatologia do estudante de Medicina. In: O universo psicológico do futuro médico. São Paulo: Casa do Psicólogo; 1999.

18. Bromberg MHPF, Kóvacs MJ, Carvalho MMMJ, Carvalho VA. Vida e morte: laços de existência. São Paulo: Casa do Psicólogo; 1996.

19. Bellodi PL. O que é um tutor? Representações do papel em um grupo de professores de Medicina durante o processo de seleção. Rev. Bras. Educ. Med. 2003; 27: 205-12.

\section{Conflito de Interesses}

Informamos que o artigo "Processo de Significação de Estudantes do Curso de Medicina diante da Escolha Profissional e das Experiências Vividas no Cotidiano Acadêmico" não apresenta Conflito de Interesses de qualquer natureza.

\section{Endereço para correspondência}

Simone da Nóbrega Tomaz Moreira

Rua Minas Novas 390 - condomínio Córdoba - casa 04

59088-725 -Neópolis - Natal - RN

E-mail: simonetomaz@hotmail.com 